\title{
How to Build Climate Resilient Health Systems:
}

\section{Reinforce the Framework Instead of Reinventing the Wheel}

\author{
Sojung Yoon MBBS MSc Public Health \\ London School of Hygiene \& Tropical Medicine, \\ London, UK \\ Sojung.Yoon1@student.lshtm.ac.uk \\ WONCA Working party on the Environment
}

\author{
Article Information \\ Epub; $\quad 01.04 .2020$ \\ Final (v3) $\quad 01.06 .2020$
}

Cite as: Yoon S. (2020) How to build climate resilient health systems; Reinforce the framework instead of re-inventing the wheel. Sushruta J Health Policy \& Opin vol13(2) DOI: $10.38192 / 13.2 .1$

\begin{abstract}
Climate change will have adverse effects on health at a population scale. Health systems need to be strengthened in order to better address changing health needs and increased demand. Frameworks exist to guide the improvement of health systems, however, they do not necessarily address adaptations to be made for climate change. This article reviews the WHO Operational Framework and identifies where this can be built upon to tackle changing health needs due to climate change.
\end{abstract}

Key words; Climate change, health systems, resilience

\section{Background}

Climate change is acknowledged as the biggest public health threat of the century. The consequences of human actions, notably the burning of fossil fuels, are affecting all countries in the world. According to the report of the Intergovernmental Panel on Climate Change (IPCC), climate change is expected to significantly increase health risks, especially in low-middle-income countries (LMICs).(1) Also, it will disproportionately affect vulnerable groups in each country, such as the poor, children and the elderly, and people with preexisting comorbidities.

With a rising exposure to climate change and a limited capacity to adapt to impacts, health systems of low-middle-income countries already face challenges. Climate change is different from other traditional public health issues in that it has effects over extended periods on a global scale, is subject to multiple uncertainties, is strongly mediated by social determinants of health, and causes diverse and interacting health impacts. Therefore, it requires strengthening health systems in collaboration with different actors at various levels. The concept of 'resilience' has been proposed to equip health systems facing climate change and other challenges such as a pandemic, natural disaster, or conflict. Building resilient health systems is to raise the capacity of health systems to absorb, adapt, and transform exposed to a shock, and still to protect and improve population health. $(2,3)$

This editorial will review the current World Health Organization (WHO) framework gaps. Lessons from adaptation responses around the world will be considered in order to suggest how to build climate resilient health systems from a people-centred perspective.

\section{WHO Operational framework and knowledge gaps}

WHO has identified six "building blocks" in health systems that are necessary to support the delivery of Universal Health Coverage and to improve health. Starting from this framework and considering a comprehensive 
health response to climate change, WHO has outlined the operational framework with ten components (Fig. 1).

This framework suggests that climate resilience should be incorporated into every sector of the health system, and as a systemic approach, interconnections between the various components are emphasized to reinforce one another. All building blocks should become climate resilient, and the health sector should extend its sphere of operations beyond itself to other sectors (e.g., water, energy, food, and agriculture).

Figure 1. Ten components comprising the WHO operational framework for building climate resilient health systems, and the main connections to the building blocks of health systems

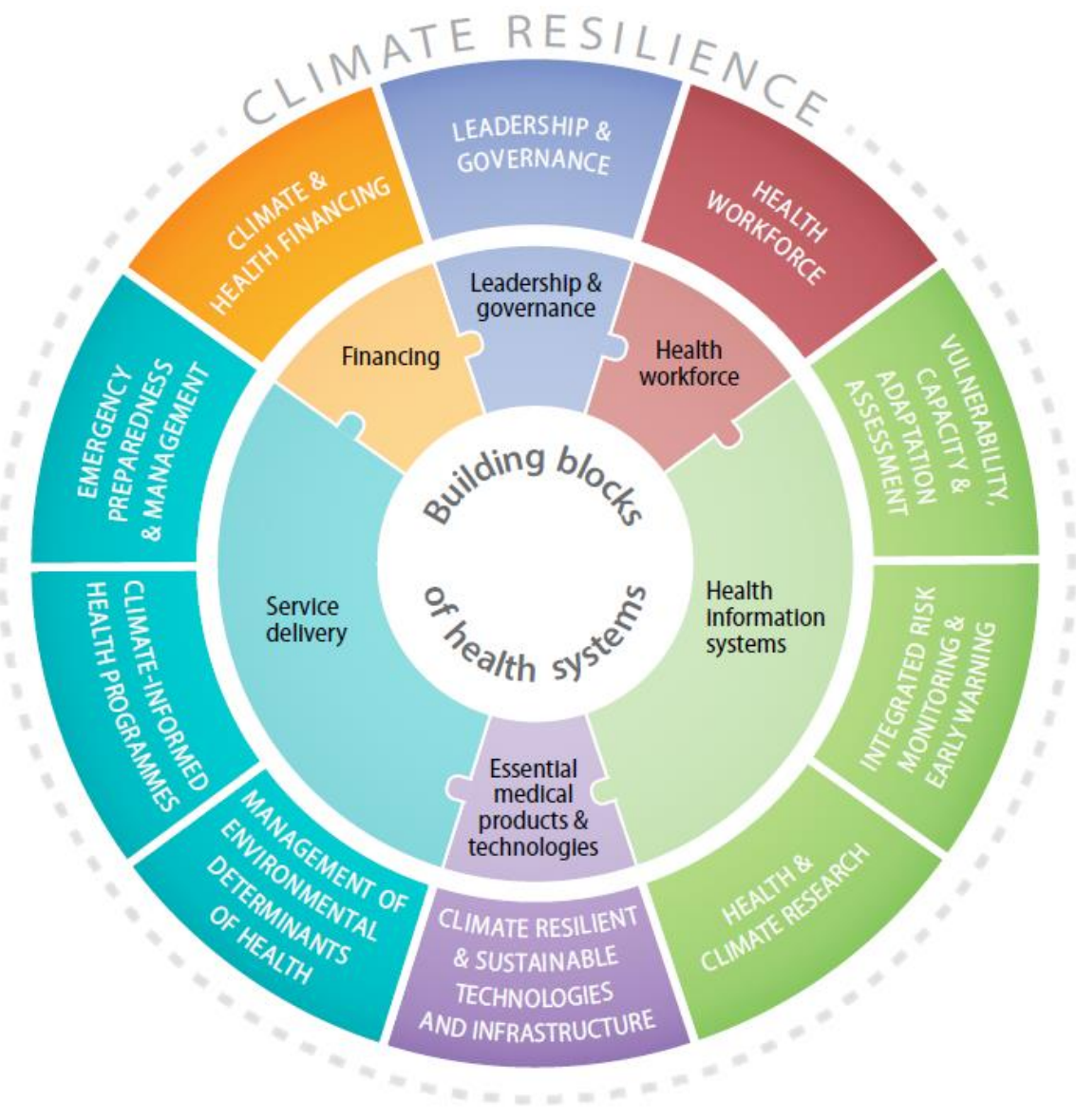

This framework can be useful in several ways. It presents a simple way to discuss the key functions of health systems. It provides a common language and a shared understanding. As it relies on already well-known six building blocks, it is easy to adapt to different contexts and ensuring all essential functions of health systems are covered. Nonetheless, many gaps could emerge from addressing the adaptation of health systems with this framework. These building blocks are considered a set of inputs that contribute to the health system.
Consequently, this framework neglects the links between inputs, outputs, and outcomes. How much can be expected and done from systemic changes? What is happening in the process by which inputs are transformed into outputs? Also, it is difficult to identify the interactions between the building blocks and different actors at various levels. Are all building blocks equally important, if not, which one would be prioritized when there are tradeoffs? How can climate resilience policies be aligned with a global governance framework 
with the partnership? How can different actors, including local and community level, reinforce each other, and collaborate against fragmentation? To address these gaps, lessons from adaptation responses in real-world need to be learned, not to reinvent the new wheel, but to reinforce the old one.

\section{A people centered perspective}

Climate change includes the interrelationship between different aspects: human beings and ecosystems. Resilience is not just about absorbing shocks from outside but also harnessing the changes in the existing systems. A people centered perspective highlights the capacity of people improving their livelihood in the face of environmental disturbances. This resilience is underpinned by human agency and empowerment by centering people as the main actors in the policy and practice.(4) Especially because social and economic determinants of health actively mediate the effects of climate change, it is essential to put people's values and needs in the center of health systems and to ensure people's participation in the policy process.

\section{Local knowledge}

Despite growing knowledge, there is a lack of enough understanding to address the links between climate change and health. It is not only about scientific evidence, but rather the capacity to combine and integrate different types of knowledge and how to prepare this knowledge for adaptation.

Evidence suggests that local and indigenous communities have been successfully adapting to climate change by developing contextspecific practices and building the resilience of their communities.(5, 6) Local knowledge is considered to provide an effective strategy for adaptation. In African Sahel, local farmers have developed several adaptation measures, including the early warning system for extreme weather events with the wealth of local knowledge on predicting weather and climate. They also have successfully achieved sustainable livelihoods by adapting to variabilities in their farming and livestock keeping.(5) Climate change adaption strategies can recognize the value of indigenous knowledge systems developed in a specific context, also because of uncertainties in the current scientific evidence base. Considering that indigenous people in most parts of the world contribute little to climate change, but are at most risk of its outcomes, their participation is essential based on the principle of justice. When their knowledge and experience are incorporated into climate change health practice, adaption will be more effective and sustainable.

\section{Community participation and delivery}

Community participation in the process of developing adaptation strategies has been emphasized in many literatures. $(7,8)$ Community empowerment can activate local capacity to improve resilience and consider equity in health systems.

Most studies suggest that sea-level rise will cause the relocation of residents at risk of floods.(9) In contrast, coastal communities in the Philippines preferred to stay and implement adaptive measures themselves to minimize the risk of floods.(8) They adapted to flooding by constructing stilted houses and raising floors with coral stone. People in Funafuti, Tuvalu, wished to remain as well because of their culture and identity.(10) Both communities considered migration as the last option, opposite to the strategy by authorities. It implies that bottom-up adaptation measures can be completely different from top-down approaches. Community-based adaptation engages people to actively cope with the health impacts of climate change, leading to the climate resilience of health systems. Furthermore, community participation is crucial for adaptation policies to gain public acceptance. Nevertheless, not all adaptation measures by communities are sustainable in the long term. As above, in the Philippines, many islanders used coral stone to raise their floors for adaptation to flooding. This measure can temporarily reduce the impacts of climate change; however, it might increase the vulnerability of communities in the long run.

\section{Multicentered relationship}

Addressing climate change and implementing adaptation responses in health systems requires engagement between various levels and types of governance. Horizontal and vertical collaboration could play an important 
role, and these collaborations require a synergistic relationship between stakeholders. Multilevel governance has been proposed as it enables combining decisions across different levels and sectors, and different institutional types at the same level.(11) It is based on participation and coordination with accountability and transparency across and within levels.

An increasing number of cities and local governments have pledged mitigation and adaptation initiatives underpinning health cobenefits. The Covenant of Mayors (CoM) is an initiative in which local authorities voluntarily commit to reduce $\mathrm{CO}_{2}$ emission. As of 2020, it involves 10,009 signatories covering 318 million people, mainly in Europe. The development of multilevel governance has facilitated the participation of small municipalities. Provinces and regions have committed to providing financial and technical support to these municipalities. Results from monitoring inventories in 2017 showed achievement of $23 \%$ reduction in $\mathrm{CO}_{2}$ emissions compared to 2005.(12)

\section{Conclusion}

Although climate change impacts through ecosystems, thinking resilience of health systems goes beyond that and stays with the people inhabiting these ecosystems. A people centered perspective can address the social determinants of health and underline the capacity of people to adapt to changes. However, there is a lack of research on a people centered perspective on climate change and adaptation. The critical lesson from the world is working 'with' people and putting their values in the center of health systems.

Resilience depends on social values regarding what we consider important and how we allocate resources. When there are trade-offs and priorities among social, economic, and environmental objectives, who decides, based on what kind of values? These questions should be discussed with the consensus of people, not be left to experts with the framework.

\section{Summary Points}

Climate change is a significant threat and requires the resilience of health systems.

A people centered perspective can be enabling to address adaptation measures by putting people's value and needs in the center of health systems.

Lessons of recognizing the local knowledge, enhancing community participation, and multilevel governance can be learned from the world.

Building climate resilient health systems depends on social values and requires the consensus of people in the society.

\section{REFERENCES}

1. An IPCC Special Report on the impacts of global warming of $1.5^{\circ} \mathrm{C}$ above pre-industrial levels and related global greenhouse gas emission pathways, in the context of strengthening the global response to the threat of climate change, sustainable development, and efforts to eradicate poverty. Intergovernmental Panel on Climate Change; 2018.

2. Blanchet K, Nam SL, Ramalingam B, Pozo-
Martin F. Governance and Capacity to Manage Resilience of Health Systems: Towards a New Conceptual Framework. Int J Health Policy Manag. 2017;6(8):431-5.

3. Operational framework for building climate resilient health systems. Geneva, Switzerland: World Health Organization; 2015. https://apps.who.int/iris/handle/10665/189 951

4. Tanner T, Lewis D, Wrathall D, Bronen $\mathrm{R}$, Cradock-Henry N, Huq S, et al. Livelihood 
resilience in the face of climate change. Nature Climate Change. 2014;5(1):23-6.

5. Nyong A, Adesina F, Osman Elasha B. The value of indigenous knowledge in climate change mitigation and adaptation strategies in the African Sahel. Mitigation and Adaptation Strategies for Global Change. 2007;12(5):78797.

6. Mahoo H, Mbungu W, Yonah I, Recha J, Radeny M, Kimeli P, et al. Integrating Indigenous Knowledge with Scientific Seasonal Forecasts for Climate Risk Management in Lushoto District in Tanzania. Copenhagen, Denmark: CGIAR Research Program on Climate Change, Agriculture and Food Security (CCAFS); 2015. Contract No.: CCAFS Working Paper no. 103.

7. Pearce T. Adaptation to climate change and freshwater resources in Vusama village, Viti Levu, Fiji. Regional environmental change. 2018.

8. Laurice Jamero $M$, Onuki $M$, Esteban $M$, Billones-Sensano XK, Tan N, Nellas A, et al.
Small-island communities in the Philippines prefer local measures to relocation in response to sea-level rise. Nature Climate Change. 2017;7(8):581-6.

9. Ayeb-Karlsson S, van der Geest K, Ahmed I, Huq S, Warner K. A people-centred perspective on climate change, environmental stress, and livelihood resilience in Bangladesh. Sustain Sci. 2016;11(4):679-94.

10. Mortreux C, Barnett J. Climate change, migration and adaptation in Funafuti, Tuvalu. Global Environmental Change. 2009;19(1):105-12.

11. Romero-Lankao P. Climate Change and Cities: Second Assessment Report of the Urban Climate Change Research Network. Cambridge, United Kingdom and New York, NY, USA; 2018. 12. Kona A, Bertoldi P, Monforti-Ferrario F, Rivas S, Dallemand JF. Covenant of mayors signatories leading the way towards 1.5 degree global warming pathway. Sustainable Cities and Society. 2018;41:568-75. 